\title{
GUIDELINE
}

\section{Vaccination of adult patients living with chronic kidney disease against SARS-CoV-2: a position statement by the South African Nephrology Society}

\author{
Malcolm Davies', Wesley van Hougenhouck-Tulleken², Nina E Diana ${ }^{3}$, MYazied Chothia $^{4}$, Jeremy Nel', Nicola Wearne ${ }^{5}$, \\ Shoyab Wadee ${ }^{6}$, Sudesh Hariparshad ${ }^{7}$ \\ 'University of the Witwatersrand, Helen Joseph Hospital, Johannesburg, South Africa; '2University of Pretoria, Steve Biko Academic \\ Hospital, Pretoria, South Africa; ${ }^{3}$ University of the Witwatersrand, Charlotte Maxeke Johannesburg Academic Hospital, \\ Johannesburg, South Africa; ${ }^{4}$ University of Stellenbosch, Tygerberg Academic Hospital, Cape Town, South Africa; ${ }^{5}$ University of Cape Town, \\ Groote Schuur Academic Hospital, Cape Town, South Africa; 'Wits Donald Gordon Medical Centre, Johannesburg, South Africa; \\ 'University of Kwazulu-Natal, Inkosi Albert Luthuli Central Hospital, Durban, South Africa.
}

\section{ABSTRACT}

Safe and effective vaccination of patients living with chronic kidney disease requires an understanding of the unique immunological milieu of this population and of their potential for disease-specific side effects. This Position Statement, issued on behalf of the South African Nephrology Society, provides recommendations for local policy development and for individual practice administration and monitoring of SARS-CoV-2 vaccinations in patients living with chronic kidney disease.

Keywords: SARS-CoV-2; vaccination; kidney disease; immunosuppression; transplantation.

\section{INTRODUCTION}

Patients living with chronic kidney disease (CKD) are at increased risk of severe COVID-19 and subsequent mortality [I]; moreover, dependence upon frequent visits to healthcare facilities for the management of CKD increases the risk of acquiring SARS-CoV-2 infection [2]. Although a fully effective treatment for COVID-19 has yet to be discovered, vaccination offers the potential to reduce the risk of infection and disease severity. The utility of this strategy in patients living with CKD remains, however, untested, since vaccine trials have largely excluded this group [3]. Furthermore, there is concern as to the efficacy of vaccination in these patients due to the immunoparesis induced by CKD [4], and the use of immunosuppressant drugs in patients with immune-mediated kidney disease or renal transplants. At present there is little guidance for clinicians on the vaccination of patients affected by CKD against SARS-CoV-2. This statement was compiled by the guidelines committee of the South African Nephrology Society through review of the available literature and consultation between nephrology and infectious disease specialists working in South Africa. The document was reviewed and authorised by the executive committee of the Society for use by its members in the counselling and management of patients undergoing vaccination for SARS-CoV-2.

\section{DISCUSSION}

Vaccination of patients living with chronic kidney disease

Although the majority of SARS-CoV-2 vaccine safety and efficacy trials have not used renal function as an exclusion criterion, the number of patients with CKD enrolled in these studies is low [5], and no report exists of chronic dialysis patients having been included in any of these

Received 05 July 2021; accepted 20 October 2021 ; published 23 November 2021. 
studies [3]. As a result, the safety profile and efficacy of SARS-CoV-2 vaccines in these patients has yet to be fully established.

Of particular concern, given the hypercoagulable state that often accompanies CKD [6], is the risk of vaccine-induced thrombotic thrombocytopaenia (VITT). VITT has been predominantly described as a rare complication of the Oxford-AstraZeneca AZDI222/ChAdOxI nCov-19 vaccine, but has also occurred in association with the Johnson \& Johnson/Janssen Ad26.COV2.S vaccine, and most commonly affects women younger than 55 years of age [7]. It is thought that endothelial injury, induced by vaccine-derived spike protein, results in platelet factor (PF4) release; complexing of PF4 with endogenous heparan sulphate leads to a hapten-driven autoantibody response with a clinical presentation similar to that of type II heparin-induced thrombotic thrombocytopenia (HITT) [7]. Although the risk of VITT in patients living with CKD is unknown, some reassurance may be drawn from the low prevalence of VITT in the general population, and the lack of apparent association of VITT with traditional venous or arterial thrombosis risk factors [7]. Considering the low probability of VITT and other potential side effects of vaccination against the disproportionate risk posed to such patients by COVID-19, the Centers for Disease Control and Prevention (CDC) advocates for the vaccination of patients on long-term outpatient dialysis [8].

The recommendation of vaccination based on this riskbenefit analysis assumes efficacy of the vaccines in preventing infection with SARS-CoV-2 or ameliorating the probability of severe COVID-19 in such an event. Progression of CKD is associated with progressive immunoparesis, featuring downgraded dendritic cell activation of lymphocytes [9] and reductions in CD4+ T-helper, CD8+ cytotoxic [10], and B-cell [4] populations. These aberrations impair the induction of immunological memory and may underlie the rapid decline in SARS-CoV-2 antibodies within 3 months in CKD patients surviving infection by the virus $[1 \mathrm{I}$.

The choice of vaccine may compensate for immunoparesis. The ability of viral vectored and mRNA vaccines to induce humoral and T-cell immunity [12] offers theoretical benefit for their use in preference to whole killed virus in such patients. Comparison of phase 3 trial reports suggests that mRNA vaccines may induce humoral immunity more reliably than replication-defective viral vector carrying pathogen gene vaccines, and the former may therefore be more effective in CKD patients [12]. In addition, limited data suggest an enhanced immune response may be elicited by administration of a third dose of mRNA vaccine [13].

\section{Vaccination in patients living with immune- mediated kidney disease}

Patients living with immune-mediated kidney disease face additional vaccine safety and efficacy concerns beyond those arising from renal dysfunction as discussed previously.

Immunological pathways important in vaccine response are known to be involved in the generation of autoimmunity and immunological disorders have been reported as rare complications of SARS-CoV-2 vaccination [14]; such observations raise the possibility of vaccine-mediated flares of pre-existing autoimmune disease. Since initial vaccine safety trials mostly excluded patients with autoimmune disease [14], the clinical validity of this theoretical concern remains largely untested. Nevertheless, because the diagnosis of COVID-19 in the setting of immune-mediated kidney disease is associated with an increased risk of both acute kidney injury and mortality [I 5], the ERA Immunonephrology Working Group recommends the vaccination of patients living with autoimmune kidney disease [14].

Where possible, the CDC recommends delaying initiation of immunosuppressive treatment until at least 2 weeks have elapsed from completion of the selected vaccination regimen [16]. In patients already receiving immunosuppression, or in those in whom initiation cannot be delayed, timing of vaccination should take into consideration the proposed immunosuppression protocol. Although limited data are available, vaccination of patients on high-dose corticosteroid therapy (20 mg prednisone equivalent or greater) is less likely to be effective [14]. Dose-dependent reductions in the response rate to influenza vaccination have been described in patients receiving mycophenolate mofetil (MMF) [17]; the threshold MMF dosage for effective vaccination against SARS-CoV-2 is, however, not known. Calcineurin inhibitors may also attenuate vaccine response [18], although protective immunisation has been demonstrated in transplant recipients receiving these agents [19]; data from influenza vaccines suggest that azathioprine does not significantly affect seroconversion [17].

Murine models suggest a dose-dependent temporal effect for cyclophosphamide on lymphocyte populations, with CD4+ T-helper and B-cell lineages decreasing from day I following pulse administration to a nadir at day 4 , followed by gradual repopulation until day 10 , when counts again begin to decline [20]. Accordingly, it has been suggested that administration of intravenous cyclophosphamide should be delayed by at least I week after vaccination, to increase the probability of successful seroconversion [2। ].

Rituximab, which inhibits the induction of the humoral response, is of particular concern in reducing the efficacy of vaccination. Previous experience with influenza vaccination 
suggests that delaying immunisation until 6 months have elapsed since the last rituximab dose improves vaccine responsiveness [22]. However, prolonged deferment of SARS-CoV-2 immunisation in anticipation of optimising immunological reactivity during the ongoing pandemic may be undesirable in this vulnerable patient group. Where possible, SARS-CoV-2 vaccination should be administered 4 weeks prior to initiation of rituximab to allow for induction of humoral immunity [2l]; for patients already receiving rituximab, a reasonable stratagem may be to proceed with immunisation with a booster dose administered 3-6 months after completion of rituximab therapy $[21,23]$. Additional confidence as to the probability of immunisation success in these patients may be obtained through the cytometric confirmation of $\mathrm{B}$-cell repopulation prior to inoculation [23].

Table I outlines recommendations for the timing of vaccination in patients receiving immunosuppression. The CDC recommends that patients on active treatment with highdose corticosteroids, alkylating agents, antimetabolites, or immunosuppressive biological agents who have received either the Pfizer-BioNTech BNTI62b2 or the Moderna mRNA- 1273 vaccine be considered for a third dose at least 28 days after completion of the 2-dose regime; it is not yet known whether booster immunisation is indicated for patients receiving the Johnson \& Johnson/Janssen Ad26. COV2.5 vaccine $[16]$.

Patients living with autoimmune kidney disease may require cyclical high-dose immunosuppression, which could reduce the anamnestic response in those previously successfully

\begin{tabular}{|c|c|}
\hline Immunosuppressant & Timing of vaccine \\
\hline Azathioprine & No delay indicated \\
\hline Calcineurin inhibitors & No delay indicated \\
\hline Cyclophosphamide (oral) & No delay indicated \\
\hline Hydroxychloroquine & No delay indicated \\
\hline $\begin{array}{l}\text { Low-dose corticosteroid } \\
\text { ( }<20 \mathrm{mg} / \mathrm{d} \text { prednisone } \\
\text { equivalent) }\end{array}$ & No delay indicated \\
\hline Mycophenolate mofetil & No delay indicated \\
\hline $\begin{array}{l}\text { High-dose corticosteroid } \\
\text { (>20 mg/d prednisone } \\
\text { equivalent) }\end{array}$ & $\begin{array}{l}\text { Preferably delay vaccination until } \\
\text { weaned to low dose }\end{array}$ \\
\hline Cyclophosphamide (intravenous) & $\begin{array}{l}\text { Delay cyclophosphamide dose } \\
\text { until I week after vaccination }\end{array}$ \\
\hline Rituximab & $\begin{array}{l}\text { Delay rituximab dose until } 4 \\
\text { weeks after vaccination }\end{array}$ \\
\hline
\end{tabular}

vaccinated against SARS-CoV-2. Whereas serial serological assay for persistence of immunity to the virus has been suggested in such cases [2I], the utility of these tests in the clinical setting has yet to be established [16].

\section{Vaccination in renal transplant recipients}

Maintenance of operational tolerance in transplant recipients requires the inhibition of $\mathrm{T}$-cell and $\mathrm{B}$-cell activation pathways, which are central to the generation of immunity by vaccination. Suppression of antigen-dependent T-cell expansion and differentiation by calcineurin inhibitors, restriction of lymphocyte proliferation by antimetabolites, $\mathrm{T}$-cell independent loss of antibody production by $\mathrm{B}$ cells due to MMF, and reduction in the expression of pro-inflammatory cytokines by corticosteroids exert an additive effect in patients on combination immunosuppression following transplantation [19]. Depleting agents, such as antithymocyte globulin (ATG), which directly reduce dendritic and T-helper cell populations, and rituximab, which targets immature B cells, inhibit multiple stages in the acquisition of immunity [19]. Reflecting these effects of long-term immunosuppressant use, reduced humoral responses to both the Pfizer-BNTI 62b2 [24] and the Moderna mRNA1273 vaccines [25] have been reported in renal transplant recipients. Of concern, $\mathrm{T}$-cell directed therapies may impair the anamnestic effector response even in those patients with documented antibody elucidation in response to vaccination [10].

Because recipients require ongoing immunosuppression, vaccination is most likely to be successful if undertaken before transplantation [26]. Temporal kinetics in the dosing of immunosuppressants results in reduced vaccination success rates in the first 3-6 months after engraftment [27]; for similar reasons, vaccination is best deferred following periods of augmented immunosuppression for the treatment of rejection, particularly if the prescribed protocol includes high-dose MMF [28]. Improved seroconversion rates have been reported in recipients on stable immunosuppression therapy who received a third dose of the Pfizer-BNT162b2 vaccine administered 61 days after the standard second dose [29]; the CDC recommends administration of a third dose of mRNA vaccine at least 28 days after completion of the 2-dose regime [16]

Vaccination has theoretically been associated with an increased risk of rejection [28]. Although rare, isolated cases of rejection following SARS-CoV-2 vaccination have been reported, and consideration should be given to monitoring graft function for signs of rejection after immunisation [30]. 
In general, SARS-CoV-2 vaccines are well tolerated by transplant recipients with a similar side-effect profile to that reported for non-immunosuppressed individuals [3।]. Despite concerns regarding the efficacy of these vaccines in such patients, the significant risk of severe COVID-19 disease and subsequent mortality in transplant recipients [32] favours the use of this intervention.

\section{Vaccines}

A summary of available anti-SARS-CoV-2 vaccines currently approved for use in African jurisdictions is presented in Table 2 [33].

\section{Killed whole virus}

Killed whole virus vaccines in use on the African continent include Sinovac's CoronaVac, Bharat Biotech's COVAXIN (BBVI52), and Sinopharm's BBIBP-CorV [33]. Limited data from small size phase 2 trials indicate seroconversion rates of $96-100 \%$ with mainly mild side effects reported (Table 2); in general, trials support a two-dose schedule [34-37]. All vaccines in this group can be stored at $2-8^{\circ} \mathrm{C}$, which facilitates their use in regions with poor healthcare infrastructure [12].

\section{Replication-defective viral vector carrying pathogen genes}

Replication-defective viral vectors are a novel vaccination strategy in which the cellular machinery of the vaccine recipient is induced to temporarily express specific pathogen antigens by RNA introduced by a viral vector, which has itself been rendered incapable of replication by gene deletion. Subsequent presentation of antigen via the major histocompatibility complexes (MHC) of the affected cell facilitates the development of an adaptive immune response [38]. The use of a replication-defective viral vector renders this technique safe for use in immunocompromised patients. Vaccines of this type in use on the African continent include AZDI222/ChAdOxInCoV-19 (Oxford-AstraZeneca), Sputnik V (Gamaleya Research), and the Johnson \& Johnson/Janssen Ad26.COV2.5 (in use only in South Africa) (Table 2). Large-scale phase 3 studies indicate an efficacy of 70-91\% for these vaccines with generally good tolerability [39-4I]; all are storable at $2-8^{\circ} \mathrm{C}[12]$.

\section{mRNA vaccines}

mRNA vaccines are an innovative vaccine technology in which mRNA for a target antigen is introduced to cells using a lipid nanoparticle (LNP) delivery vehicle. Once endocytosed, LNP facilitates release of mRNA, which is then translated into antigen that is presented by the cell to the immune system using MHC complexes [42]. mRNA vaccines offer several advantages over conventional vaccination strategies, including improved cellular immunogenicity (via antigen presentation on MHC class I), absolute reduction in risk of both vaccine infection (due to independence from a viral vector) and insertional mutagenesis (due to use of non-replicating mRNA), and increased potential for rapid development and manufacture [42]. Both the PfizerBioNTI62b2 and the Moderna mRNA-I 273 mRNA vaccines are in use in the African context (Table 2). Largescale phase 3 studies indicate an efficacy of $95 \%$ with mainly mild adverse effects $[43,44]$. Although the vaccines are stable at $2-8^{\circ} \mathrm{C}$ for a limited period, long-term storage requires low temperature refrigeration $\left(-20^{\circ} \mathrm{C}\right.$ to $\left.-70^{\circ} \mathrm{C}\right)$, limiting the widespread use of these vaccines [12].

\section{Immunological monitoring}

Immunity against future infection by a pathogen requires the acquisition of both humoral and cellular response arms. Since the relative contribution of either response to protection against SARS-COV-2 is unknown, assessment of immunity following vaccination should ideally measure both [45].

Cellular uptake of the SARS-CoV-2 virion in preparation for replication is accomplished by binding of the receptor binding domain (RBD) of the SI subunit of the spike glycoprotein to surface expressed angiotensin-converting enzyme 2, followed by S2-mediated fusion of the viral and host cell membranes [46]. Whereas the S2 subunit is highly conserved in coronaviruses, the SI unit is relatively specific for SARS-CoV-2 and forms the antigenic target for the majority of available vaccines [45]. Available serological tests for humoral response to SARS-CoV-2 are able to detect IgA, IgM, IgG or total immunoglobulin level against nucleocapsid (N) or spike glycoprotein (S) specificities [45]; only those that are specific for anti-SI IgG antibody are suitable for determining vaccine humoral effect.

Although anti-RBD IgG titres remain elevated for at least 6 months in survivors of SARS-CoV-2 infection [47], the total duration of detectable persistence of antibody in either natural or post-vaccination immunity is not known, and the threshold titre for humoral protection against infection has not been determined [46]. It is therefore unclear whether the natural history of IgG expression in COVID-19 survivors can be extrapolated to post-vaccination immunological monitoring.

Up to $40 \%$ of SARS-CoV-2 infected patients may fail to mount a detectable antibody response to the virus [45]; significantly, memory $T$ cells have been extracted from convalescent antibody-negative patients [48], suggesting 
Table 2. SARS-CoV-2 vaccines in use in Africa.

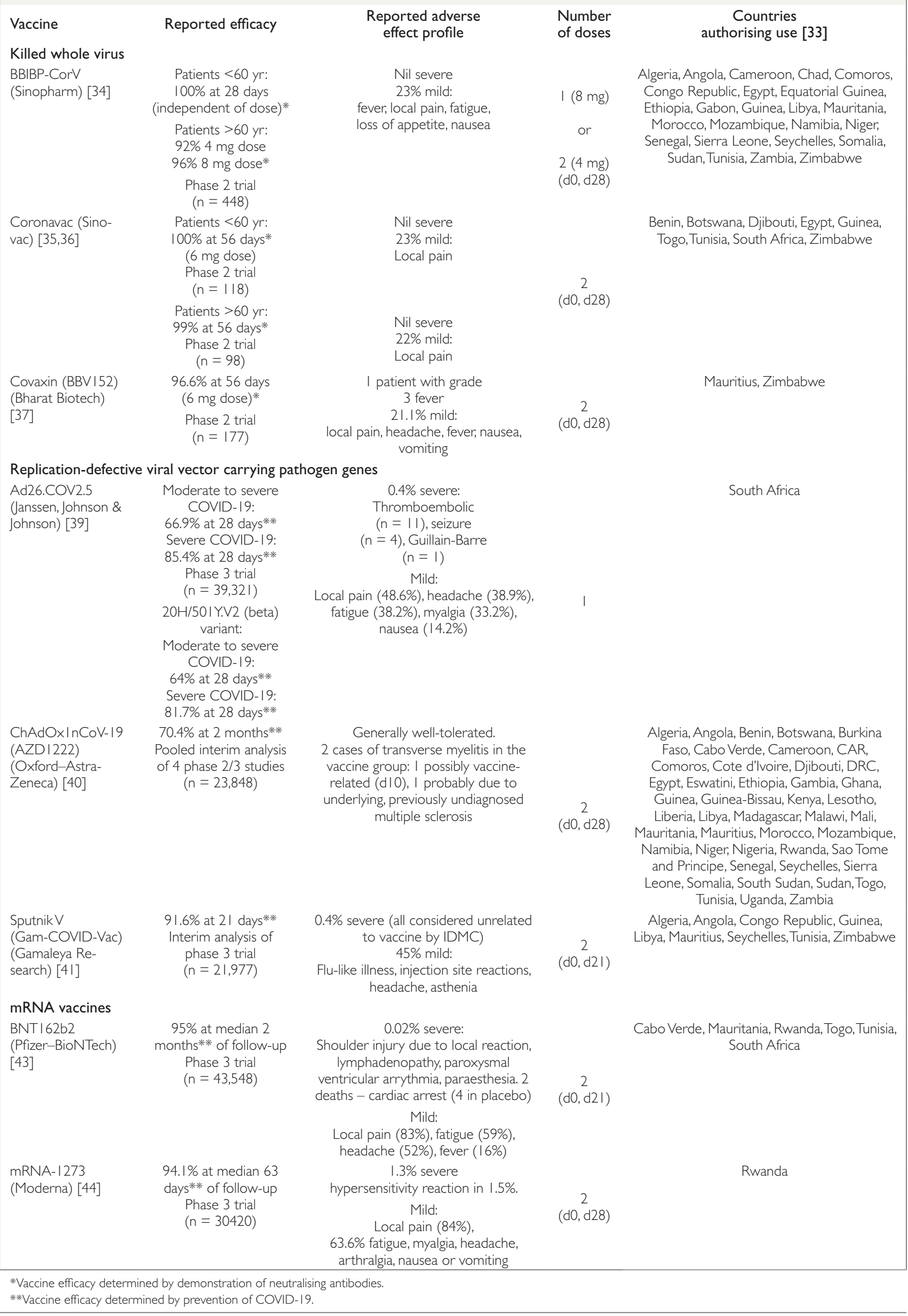


that the cellular arm of the immune response may provide protection against subsequent infection. Thus, evaluation of antibody titre alone after administration of vaccines capable of inducing a $T$-cell response (Oxford-AstraZeneca ChAdOxInCoV-19, Pfizer-BioNTI62b2 and Moderna mRNA- 1273) [45] may not accurately reflect the potency of immunisation achieved.

In view of these limitations, neither the US Federal Drug Administration [49] nor the CDC [50] currently recommends existing serological tests for the evaluation of postvaccination immunity.

\section{RECOMMENDATIONS}

Consideration of the available literature suggests the following approaches to the vaccination of patients living with CKD against SARS-CoV-2:

I. All patients living with CKD, including those with immunemediated kidney disease and renal transplant recipients, constitute a high-risk group for the develop-ment of severe COVID-19 [1,2] and should be offered vaccination for SARS-CoV-2, including those with documented antecedent infection with SARS-CoV-2.

I.I All such patients should therefore receive the first available vaccine with documented efficacy in preference to waiting for vaccine with perceived higher efficacy.

1.2 However, if available, all such patients should preferably be offered vaccination with mRNA vaccines, in view of apparent enhanced reliability of reactogenicity [12].

2. Steps should be taken in all such patients receiving vaccination against SARS-CoV-2 to limit and to monitor for potential side effects.

2.I Patients with a known allergy to PEG (LNP stabiliser) should not be offered vaccination with either mRNA-1273 or BNT162b2 but should be offered vaccination with either a replication-deficient viral vector vaccine or a killed whole-virus vaccine. Similarly, patients with a known allergy to polysorbate 80 (stabiliser in replication-deficient viral vector vaccines) should be offered vaccination with either an mRNA or a whole killed virus vaccine and should not receive either the $\mathrm{ChAdO} \times 1 \mathrm{nCoV}-19$ (AZD I222) or the Ad26.COV2.5 vaccine [14].

2.2 A low threshold for investigation for VITT should be maintained in female patients under the age of 55 immunised with the Ad26.COV2.5 vaccine, who report symptoms suggestive of cerebral venous sinus thrombosis, deep vein thrombosis, or pulmonary thromboembolism [7].

2.3 The possibility of acute rejection should be considered in any transplant recipient manifesting a sudden deterioration in graft function after recent vaccination.

3. The timing of vaccination in patients living with immunemediated kidney disease and in renal transplant recipients should be individualised in the context of prescribed or planned immunosuppression.

3.I Where possible, initiation of immunosuppression should be delayed by two to four weeks to allow for adequate immunisation $[16,2 \mid]$.

3. I.I In cases requiring emergent therapy, intravenous pulse cyclophosphamide infusion should, where possible, be delayed by at least one week following vaccination $[2 \mathrm{l}]$.

3.2 In patients already receiving corticosteroids, vaccination should, where possible, be delayed until the prescribed dose is less than $20 \mathrm{mg} /$ day prednisone or equivalent [2I].

3.3 Where local policy allows, all patients on high-dose immunosuppression regimes or regimes which include biologics, who receive an mRNA vaccine, should be offered a third vaccine dose administered at least 28 days after the scheduled second dose $[13,16,29]$.

3.3.I In patients receiving rituximab who receive an mRNA vaccine, booster vaccination should be administered 3-6 months after completion of treatment course, or once B-cell repopulation is confirmed by peripheral blood flow cytometry $[21,23]$

4. Routine monitoring for immunological response to vaccination is not currently indicated in the clinical setting, regardless of the perceived immunological competency of the individual patient $[16,49,50]$.

5. All patients living with CKD should continue to practise masking, hand hygiene, and social distancing regardless of vaccination status.

\section{CONCLUSIONS}

Patients living with CKD are at high risk of severe COVID-19, and dependence on hospital-based specialist care for treatment of CKD increases individual risk of contracting SARS-CoV-2. No satisfactory treatment protocol for COVID-I9 is currently available; however, hope 
of relief from the pandemic is now at hand in the form of novel vaccines. To optimise the success of immunisation of this vulnerable patient population, nephrologists are urged to acquaint themselves with all aspects of SARSCoV-2 vaccination.

\section{Conflicts of interest}

The authors have no conflicts of interest to declare.

\section{REFERENCES}

I. Zadori N, Vancsa S, Farkas N, Hegyi P, Eross B. The negative impact of comorbidities on the disease course of COVID-19. Int Care Med. 2020;46(9): I 784- 1786 doi: 10.1007/s00 I34-020-06 I 6I-9.

2. Corbett RW, Blakely S, Nitsch D, Loucaidou M, McLean A, Duncan $\mathrm{N}$, et al. Epidemiology of COVID- 19 in an urban dialysis center. J Am Soc Nephrol. 2020;3 I (8): I 8 I 5- I 823 doi: 10. I68 I/ASN.2020040534.

3. Kliger AS, Silberzweig J. COVID- 19 and dialysis patients: unresolved problems in early 2021. J Am Soc Nephrol. 2021;32(5): I 01 8- 1020 doi: https://doi.org/10.1681/ASN.2020121766.

4. Betjes $M G H$. Immune cell dysfunction and inflammation in end-stage renal disease. Nat Rev Nephrol. 2013;9(5):255-265 doi: 10. I038/ nrneph.2013.44.

5. Glennn DA, Hegde A, Kotzen E, Walter EB, Kshirsagar AV, Falk R, et al. Systemic review of safety and efficacy of COVID- 19 vaccines in patients with kidney disease. Kidney Int Rep. 2021;6(5): I 407-I 4 I0 doi: https://doi.org/10.1016/j.ekir.2021.02.01।.

6. Pavord S, Myers B. Bleeding and thrombotic complications of kidney disease. Blood Reviews 201 I;25(6):27I-278 doi: https://doi. org/ | 0.1016/j.blre.201 1.07.00।.

7. Kantarcioglu B, lqbal O, Walenga JM, Lewis B, Lewis J, Carter CA, et al. An update on the pathogenesis of COVID-19 and the reportedly rare thrombotic events following vaccination. Clin Appl Thrombosis Hemostasis 201 1;27: 107602962 I I 02 | 498 doi: 10.1 177/107602962|1021498.

8. Centers for Disease Control. Vaccinating dialysis patients and healthcare personnel. Available from https://www.cdc.gov/vaccines/ covid-19/planning/vaccinate-dialysis-patients-hcp.html [accessed 04/07/202I].

9. Syed-Ahmed M, Narayanan M. Immune dysfunction and risk of infection in chronic kidney disease. Adv Chronic Kidney Dis. 2019;26( I):8- I 5 doi: https://doi.org/ | 0.1053/j.ackd.2019.01.004.

10. Costa E, Lima M, Alves JM, Rocha S, Rocha-Pereira P, Castro E, et al. Inflammation, T-cell phenotype, and inflammatory cytokines in chronic kidney disease patients under hemodialysis and its relationship to resistance to recombinant human erythropoietin therapy. J Clin Immunol. 2008;28(3):268-275 doi: I0. I007/s I0875007-9168-x.

I I. Labriola L, Scohy A, Seghers F, Perlot Q, De Greef J, Desmet C, et al. A longitudinal, 3-month serologic assessment of SARS-CoV-2 infections in a Belgian hemodialysis facility. Clin J Am Soc Nephrol. 202 I; | 6(4):6 I3-6I4 doi: https://doi.org/I0.22 I 5/CJN. I 2490720.

12. Windpessl M, Bruchfeld A, Anders H-J, Kramer $\mathrm{H}$, Waldman M, Renia L, et al. COVID- 19 vaccines and kidney disease. Nat Rev Nephrol. 202 I; | 7:29 I-293 doi: https://doi.org/I0.1038/s4I 58I-02I 00406-6.

13. Ducloux D, Colladant M, Chabannes M, Yannraki M, Courivard C. Humoral response after three doses of BNT162b2 mRNA COVID- 19 vaccine in patients on haemodialysis. Kidney Int.
14. Kronbichler A, Anders H-J, Fernandez-Juarez GM, Floege J, Goumenos D, Segelmark M, et al. Recommendations for the use of COVID- 19 vaccines in patients with immune-mediated kidney diseases. Nephrol Dial Transplant. 202 1;36(7): I I60- I 168 doi: 10.1093/ndt/gfab064/6163301.

15. Waldman M, Soler MJ, García-Carro C, Lightstone L, Turner-Stokes T, Griffith M, et al. Results from the IRoc-GN international registry of patients with COVID-19 and glomerular disease suggest close monitoring. Kidney Int. 2021;99( I):227-237 doi: https://doi. org/10.1016/j.kint.2020.10.032.

16. Centers for Disease Control and Prevention. Considerations for use of an additional mRNA COVID- 19 vaccine dose after an initial 2-dose primary mRNA COVID-19 vaccine series for immunocompromised people. Available from https://www.cdc.gov/ vaccines/covid- | 9/clinical-considerations/covid-19-vaccines-us.html [accessed 20/08/202I].

17. Scharpé J, Evenepoel P, Maes B, Bammens B, Claes K, Osterhaus AD, et al. Influenza vaccination is efficacious and safe in renal transplant recipients. Am J Transplant. 2008;8(2):332-337 doi: | 0. | | | |/j. 600-6 | 43.2007.02066.x.

18. Versluis DJ, Beyer WE, Masurel N, Wenting GJ, Weimar W. Impairment of the immune response to influenza vaccination in renal transplant recipients by cyclosporine, but not azathioprine. Transplantation 1986;42(4):376-379 doi: 10.1097/00007890198610000-00009.

19. Gangappa S, Kokko KE, Carlson LM, Gourley T, Newell KA, Pearson TC, et al. Immune responsiveness and protective immunity after transplantation. Transplant Int. 2008;2I (4):293-303 doi: I 0. I | | | /j. I 432-2277.2007.0063 I.x.

20. Al-Homsi AS, Roy TS, Cole K, Feng Y, Duffner U. Post-transplant high-dose cyclophosphamide for the prevention of graft-versus-host disease. Biol Blood Marrow Transplant. 2015;2I (4):604-6I I doi: https://dx.doi.org/10.1016/j.bbmt.2014.08.014.

2I. Ferretti F, Cannatelli R, Benucci M, Caramgnola S, Clementi E, Danelli $P$, et al. How to manage COVID- 19 vaccination in immune-mediated inflammatory diseases: an expert opinion by IMIDs study group. Front Immunol. 202 I; | 2:656362 doi: I0.3389/fimmu.2021.656362.

22. Westra J, van Assen S, Wilting KR, Land J, Horst G, de Haan A, et al. Rituximab impairs immunoglobulin (Ig)M and $\lg G$ (subclass) responses after influenza vaccination in rheumatoid arthritis patients. Clin Exp Immunol. 20 I 4; I 78( I ):40-47 doi: I0. I I I I/cei. I 2390.

23. Baker D, Roberts CAK, Pryce G, Kang AS, Marta M, Reyes S, et al. COVID- 19 vaccine-readiness for anti-CD20-depleting therapy in autoimmune diseases. Clin Exp Immunol. 2020;202(2): |49- I6I doi: | 0.1 | | |/cei. I 3495

24. Grupper A, Rabinowitch L, Schwartz D, Schwartz IF, Ben-Yehoyada $M$, Shashar $M$, et al. Reduced humoral response to mRNA SARSCoV-2 BNTI 62 b2 vaccine in kidney transplant recipients without prior exposure to the virus. Am J Transplant. 202 I; 2 I (8):27 I9-2726 doi: 10.1 | | |/ajt. 66 |5.

25. Benotmane I, Gautier-Vargas G, Cognard N, Olagne J, Heibel F, Braun-Parvez L, et al. Weak anti-SARS-CoV-2 antibody response after the first injection of an mRNA COVID- 19 vaccine in kidney transplant recipients. Kidney Int. 2021 ;99(6): | 487- 489 doi: https:// doi.org/1 0.1016/j.kint.2021.03.014.

26. Chong PP, Avery RK. A comprehensive review of immunization practices in solid organ transplant and hematopoietic stem cell transplant recipients. Clin Ther. 2017;39(8): I 58I-98 doi: https://doi. org/10.10 16/j.clinthera.2017.07.005.

27. Kumar D, Blumberg EA, Danziger-Isakov L, Kotton CN, Halasa NB, Ison MG, et al. Influenza vaccination in the organ transplant recipient: review and summary recommendations. Am J Transplant. 20 I I; I I ( I0):2020-30 doi: https://doi. org/|0. | | | |/j. |600-6|43.20||.03753.x. 
28. Babu TM, Kotton CN. Immunizations in chronic kidney disease and kidney transplantation. Curr Treat Options Infect Dis. 202 I; 1 3:47-65 doi: 10.1007/s40506-021-00248-7.

29. Kamar N, Abravanel F, Marion O, Couat C, Izopet J, Del Bello A. Three doses of an mRNA COVID- 19 vaccine in solid-organ transplant recipients. New Eng J Med. 202 I; 385:66 I-662 doi: 10.1056/NEJMc2108861.

30. Del Bello A, Marlon O, Delas A, Congy-Jolivet N, Colombat M, Kamar N. Acute rejection after anti-SARS-CoV-2 mRNA vaccination in a patient who underwent a kidney transplant. Kidney Int. 202 I; I00( I ):238-239 doi: https://doi.org/ I 0. I 0 | 6/j.kint.202 1.04.025.

31. Ou MT, Boyarsky BJ, Motter JD, Greenberg RS, Teles AT, Ruddy JA, et al. Safety and reactogenicity of 2 doses of SARS-CoV-2 vaccination in solid organ transplant recipients. Transplantation. 2021; 105( I 0):2170-2174 doi 10.1097/tp.0000000000003780.

32. Pereira MR, Mohan S, Cohen DJ, Husain SA, Dube GK, Ratner LE, et al. COVID- 19 in solid organ transplant recipients: initial report from the US epicenter. Am J Transplant. 2020;20(7): I 800- I 808 doi: https://doi.org/|0.1 I | //ajt. 1594|.

33. CDC Africa. COVID-19 vaccination Africa: CDC vaccination dashboard. Available from https://africacdc.com/COVID-19vaccination/ [accessed 21/06/202I].

34. Xia S, Zhang Y, Wang Y, Wang H, Yang Y, Gao GF et al. Safety and immunogenicity of an inactivated SARS-CoV-2 vaccine, BBIBP-CorV: a randomised, double-blind, placebo-controlled, phase I/2 trial. Lancet Infect Dis. 2020;2I ( ):39-5 I doi: 10.1016/ SI473$3099(20) 30831-8$.

35. Zhang Y, Zeng G, Pan H, Li C, Hu Y, Chu K et al. Safety, tolerability, and immunogenicity of an inactivated SARS-CoV-2 vaccine in healthy adults aged 18-59 years: a randomised, double-blind, placebocontrolled, phase I/2 clinical trial. Lancet Infect Dis. 2021;21 (2): I 8 I I 92 doi: I 0. I 0 | 6/S | 473-3099(20)30843-4.

36. Wu Z, Hu Y, Xu M, Chen Z, Yang W, Jiang Z, et al. Safety, tolerability, and immunogenicity of an inactivated SARS-CoV-2 vaccine (CoronaVac) in healthy adults aged 60 years and older: a randomised, double-blind, placebo-controlled, phase I/2 clinica trial. Lancet Infect Dis. 202 I;2I (6):803-8I 2 doi: 10.10 I 6/S I4733099(20)30987-7

37. Ella R, Vadrevu KM, Jogdand $H$, Prasad S, Reddy S, Sarangi $V$, et al. Safety and immunogenicity of an inactivated SARS-CoV-2 vaccine, BBV I52: interim results from a double-blind, randomised, multicentre, phase 2 trial, and 3-month follow-up of a double-blind, randomised phase I trial. Lancet Infect Dis. 2021;2I (5):637-646 doi: https://doi. org/10.1016/S I 473-3099(20)30942-7.

38. Vrba SM, Kirk NM, Brisee ME, Liang Y, Ly H. Development and applications of viral vectored vaccines to combat zoonotic and emerging public health threats. Vaccines 2020;8(4):680 doi: I0.3390/ vaccines 8040680

39. Sadoff J, Gray G, Vandebosch A, Caardenas V, Shukarev G, Grinsztejn B, et al. Safety and efficacy of single-dose AD26.COV2.S vaccine against Covid- 19. N Eng J Med. 202 1;384:2 I87-220 I doi: 10.1056/NEJMoa2 101544.

40. Voysey M, Clemens SAC, Madhi SA, Weckx LY, Folegetti PM, Aley PK, et al. Safety and efficacy of the ChAdOxI nCoV-19 vaccine (AZD I222) against SARS-CoV-2: an interim analysis of four randomised controlled trials in Brazil, South Africa, and the UK. Lancet 202 1;397( I 0269):99- I I I doi: https://doi.org/ 10.1016/ SOI40-6736(20)3266 I-I.

4I. Logunov DY, Dolzhikova IV, Shchleblyakov DV, Tukhvatulin AI, Zubkova OV, Dzhaurullaeva AS, et al. Safety and efficacy of an rAd26 and rAd5 vector-based heterologous prime-boost COVID-19 vaccine: an interim analysis of a randomised controlled phase 3 trial in Russia. Lancet 202 1;397( | 0275):67 I-68 I doi: https://doi.org/10.1016/ SOl40-6736(2I)00234-8.
42. Pardi N, Hogan MJ, Porter FW, Weissman D. mRNA vaccines - a new era in vaccinology. Nat Rev Drug Discovery 20 I 8; I 7(4):26 I-279 doi: 10.1038/nrd.2017.243.

43. Polack FP, Thomas SJ, Kitchin N, Absalon J, Gurtman A, Lockhart S, et al. Safety and efficacy of the BNTI62b2 mRNA Covid-19 vaccine. N Eng J Med. 2020;383:2603-26I 5 doi: I0. I056/NEJMoa2034577.

44. Baden LR, El Sahly HM, Essink B, Kotloff K, Frey S, Novak R, et al. Efficacy and Safety of the mRNA-I 273 SARS-CoV-2 vaccine. N Eng J Med 2021;384:403-4 I 6 doi: 10.1056/NEJMoa2035389.

45. Ong DSY, Fragkou PC, Schweitzer VA, Chemaly RF, Moschopoulos CD, Skevaki C. How to interpret and use COVID- 19 serology and immunology tests. Clin Microbiol Infection 2021; 27(7):981-986 doi: https://doi.org//0.1016/j.cmi.2021.05.001.

46. Tai W, He L, Zhang X, Pu J, Voronin D, Jiang S, Zhou Y, Du L. Characterization of the receptor-binding domain (RBD) of 2019 novel coronavirus: implication for development of RBD protein as a viral attachment inhibitor and vaccine. Cell Molec Immunol. 2020; 1 7:6 | 3-620 doi: https://doi.org/ | 0. I 038/s4 | 423-020-0400-4.

47. L'Huillier AG, Meyer B, Andrey DO, Arm-Vernez I, Baggio S, Didierlaurent $A$, et al. Antibody persistence in the first 6 months following SARS-CoV-2 infection among hospital workers: a prospective longitudinal study. Clin Microbiol Infect. 2021;27(5):784 El-874.E8 doi: https://doi.org/10.10 I6/j.cmi.2021.01.005.

48. Sekine T, Perez-Potti A, Riviera-Ballesteros $O$, Stralin K, Gorin J-B, Olsson $A$, et al. Robust $T$ cell immunity in convalescent individuals with asymptomatic or mild COVID-19. Cell 2020; 183(I): 158-168 doi: https://doi.org/10.1016/j.cell.2020.08.017.

49. Federal Drug Administration. Antibody testing is not currently recommended to assess immunity after COVID-19 vaccination: FDA safety communication. 19 May 2021. Available from https://www.fda. gov/medical-devices/safety-communications/antibody-testing-notcurrently-recommended-assess-immunity-after-covid- 19-vaccinationfda-safety [accessed 04/07/202 I]

50. Centers for Disease Control and Prevention. Interim guidelines for COVID- 19 antibody testing in clinical and public health settings. 17 March 2021. Available from https://www.cdc.gov/coronavirus/2019ncov/lab/resources/antibody-tests-guidelines.html [accessed 04/07/202 I] 